\title{
High division and variation in brachial artery branching pattern.
}

\author{
Dr. Chandrika Teli ${ }^{1}$, Dr. Nilesh N. Kate ${ }^{2}$, Dr. Paarthipan N. ${ }^{3}$ \\ ${ }^{I}$ (Assistant Professor, Department Of Anatomy, Meenakshi Medical College Hospital \& RI, Kancheepuram, \\ Tamil Nadu, MAHER UNIVERSITY, INDIA) \\ ${ }^{2}$ (Assistant Professor, Department Of Physiology, Meenakshi Medical College Hospital \& RI, Kancheepuram, \\ Tamil Nadu, MAHER UNIVERSITY, INDIA) \\ ${ }^{3}$ (Associate Professor, Department Of Radiology, Meenakshi Medical College Hospital \& RI, Kancheepuram, \\ Tamil Nadu, MAHER UNIVERSITY, INDIA)
}

\begin{abstract}
In a 45 year male cadaver unusual variation of right brachial artery branching was observed. Brachial artery also showed high division in to radial and ulnar artery in upper third of arm. The posterior circumflex humeral artery, profunda brachii artery and superior ulnar collateral artery all arose from one common trunk in proximal part of brachial artery before its termination. In this report we endeavor to discuss the relevance of embryogenesis and clinical importance.
\end{abstract}

Key words: Brachial artery, Posterior circumflex humeral artery, Profunda brachii artery, superior ulnar collateral artery, high division of brachial artery

\section{INTRODUCTION}

The brachial artery, a continuation of the axillary artery, begins at the distal border of the tendon of teres major and ends about a centimeter distal to the elbow joint by dividing into the radial and ulnar arteries. The artery is crossed superficially by the median nerve from lateral to medial. ${ }^{(1)}$ The brachial artery gives origin to profunda brachii, nutrient, superior and inferior ulnar collateral, muscular, radial, and ulnar arteries. The profunda brachii artery, a large branch from the brachial artery, distal to the teres major, follows the radial nerve closely between the long and medial head of the triceps and then in the radial groove. It gives origin to radial collateral and middle collateral arteries. ${ }^{(1)}$

According to Compendium of Human Anatomic Variation, ${ }^{(2)}$ major variations are present in about $25 \%$ of the subjects studied for the brachial artery. The variations in the form of high proximal division into terminal branches occur in the radial artery (15\%), ulnar artery $(2 \%)$ and common interosseous artery. This high division may occur at any point in the normal course of the vessel, but it is more common in the middle third. The two vessels run parallel to each other to the bend of the elbow, in the usual position of the brachial artery. From this point, one branch follows the normal course of the radial artery through the forearm and the other one takes the normal course of the ulnar artery. This arrangement is considered a simple high division of the brachial artery. ${ }^{(2)}$ In the present case report, we focused on the anatomical topography of this arterial variation and discussed its morphological and clinical significance.

\section{Case Report}

The variation was observed in a male cadaver aged about 45 year during a routine dissection class for undergraduates. The findings observed on the right upper extremity are described below.

\subsection{In the arm}

-The posterior circumflex artery, profunda brachii artery and superior ulnar collateral artery all arose from one common trunk in proximal part of brachial artery before its termination (Figure :1 )

- The brachial artery divided into radial and ulnar arteries, about $1.5 \mathrm{~cm}$ distal to the lower border of teres major muscle, in the upper third of arm. (Figure: 2 )

- The median nerve crossed radial artery from lateral to medial side as it traveled to cubital fossa

- The radial and ulnar arteries descended parallel to each other in the arm, over the biceps brachii muscle

\subsection{In the cubital fossa}

-The radial artery passed through the apex of the fossa, lying medial to median nerve. While the ulnar artery passed deep to the deep head of the pronator teres muscle. (Figure: 2)

- The branching of the radial and ulnar arteries was normal in forearm. 


\section{Discussion}

Anomalies of the forelimb arterial tree are fairly common. This is mainly because of their multiple and plexiform sources, the temporal succession of emergence of principal arteries, anastomoses and periarticular networks and functional dominance followed by regression of some paths. ${ }^{(1)}$

High origin of radial and ulnar artery forms the highest percentage of variations of brachial artery. High origin of radial artery occurance is 3 to $15 \%$, as reported by different authors. ${ }^{(3,4,5,6)}$ The parent trunk being axillary artery in $12.5 \%$, proximal $1 / 3$ of brachial artery in $62.5 \%$ and middle $1 / 3$ of brachial artery in $25 \%{ }^{(6)}$ They found high origin of ulnar artery in $1 \%$ cases only and compared it with similar reports by others. ${ }^{(5,}$ ${ }^{6)}$ The present case variation can be classified as superficial brachioradial artery which is high origin of radial artery with course superficial to forearm flexors. ${ }^{(7)}$ Origin of profunda brachii artery is quite variable, arising as a common trunk with superior ulnar collateral artery in $22.3 \%$ cases, ${ }^{(3)}$ arising as a common trunk with posterior circumflex humeral artery ${ }^{(3,8)}$ either before entry of posterior circumflex humeral artery in quadrangular space or after its entry in to quadrangular space. In present case it was before entry into quadrangular space. A rare case of origin of subscapular, anterior and posterior circumflex humeral, profunda brachii artery and ulnar collateral arteries from a common trunk from the third part of the axillary artery is reported. Its commencement was passing between two roots of median nerve. ${ }^{(9)}$ Profunda brachii arising from posterior circumflex humeral associated with high division of brachial artery is also reported. ${ }^{(10)}$ Another case of origin of subscapular artery, circumflex humerals, radial collateral, middle collateral, superior ulnar collateral artery all arising from one trunk from third part of axillary artery is also noted. ${ }^{(11)}$

The unusually short segment brachial artery with its high up division into radial and ulnar arteries as observed in the present study can be explained in the light of embryological development.

The early limb bud receives blood via inter segmental arteries, which contribute to a primitive capillary plexus. At the tip of the limb bud there is a terminal plexus that is constantly renewed in a distal direction as the limb grows. Later one main vessel supplies the limb and the terminal plexus; it is termed the axis artery. The aforesaid terminal plexus at the tip of the limb bud is separated from the outer ectodermal sleeve of the limb by an avascular zone of mesenchyme. This avascular region contains an extracellular matrix consisting largely of hyaluronic acid. Removal of this hyaluronic acid by hyaluronidase results in vascularization of the tissue since partial degradation products of hyaluronic acid are angiogenic. Thus ectodermal-mesenchymal interactions and extracellular matrix components are controlling the initial patterning of blood vessels within the limb. ${ }^{(12)}$ In the upper limb bud the axis artery is derived from the lateral branch of the seventh inter segmental artery (subclavian). The arterial trunk grows outwards along the ventral axial line and terminates in the deep plexus in the developing hand. Proximal part of the main trunk forms the axillary and brachial artery and its distal part persists as the anterior interosseous artery and the deep palmar arch. The radial and ulnar arteries are the latest arteries to appear in the forearm from the axis artery (brachial). Initially the radial artery arises more proximally than the ulnar artery. Later, it establishes a new connection with the main trunk at or near the level of origin of the ulnar artery and the upper portion of its original stem usually disappears to a large extent more proximally from the brachial artery leading to the formation of an unusually short segment and slightly narrow brachial artery which bifurcated into radial and ulnar arteries at a more proximal level near the middle of the arm. The profunda brachii artery took origin from the short segment brachial artery along with posterior circumflex humeral artery and superior ulnar collateral artery. However, the subsequent distribution of the radial and ulnar arteries was normal. It is pertinent to mention here that the normal vascular development including the patterning of the blood vessels is influenced greatly by local hemodynamic factors. Altered hemodynamic environment may give rise to variant patterning of blood vessels. ${ }^{(13)}$ Diagnostically this type of variation may disturb the evaluation of angiographic images. Further knowledge of such variation has got clinical importance especially in the field of orthopedic, plastic and vascular surgeries. ${ }^{(6)}$ Last but not the least, knowledge of this variation is important for the clinicians in day to day practice for measurement of blood pressure using sphygmomanometer cuff in the arm.

\section{References}

[1] Williams PL, Bannister LH, Berry MM, Collins P, Dyson M, Dussek JE, Ferguson MW, eds. Gray’s Anatomy. 38th Ed., London, Churchill Livingstone. 1999; 319, 1539.

[2] Bergman RA, Thompson SA, Afifi AK, Saadeh FA. Compendium of human anatomic variation. Baltimore: Urban \& Schwarzenberg; 1988 .

[3] Anson,B.J:morris.Human Anatomy in;the cardiovascular system-Arteries and veins. Thoms, M.Edr.Mc Grow Hill Book c. new York.pp708-724[1966].

[4] De Garis CF, Swartley WB. The axillary artery in white and Negro stocks. Am J Anat. 1928:41; 353-97.

[5] Muller E (1903) Beitra\$ge zur Morphologie des Gefa\$sssystems.I. Die Armarterien des Menschen. Anatomische Hefte 22,377-575.

[6] Karlsson S, Niechajev I A (1982) Arterial anatomy of the upper extremity. Acta Radiologica 23, 115-121

[7] M. Rodriguez-Niedenfu HR, T. Vazquez, L. Nearn, B. Ferreira, I. Parkin, J. R. Sannudo Variations of the arterial pattern in the upper limb revisited: a morphological and statistical study, with a review of the literature J. Anat. (2001) 199, pp. 547-566, 
[8] Keen JA. A study of the arterial variations in the limbs, with special reference to symmetry of vascular patterns. Am J Anat. 1961; 108: 245-261. T. Ramesh Rao; Prakashchandra Shetty, R. Suresh: Abnormal Branching Pattern of the Axillary Artery and its Clinical SignificanceInt. J. Morphol. v.26 n.2 Temuco jun. 2008

[9] Sampath Madhyastha, Soubhagya R. Nayak,Ashwin Krishnamurthy, Sujatha D’Costa, Asha Anu Jose, Kumar M.R. Bhat : Case report of high origin of radial, ulnar, and profunda brachii arteries, its clinical implications and review of the literature $\mathbf{J}$ Vasc Bras

[10] Vijaya Paul Samuel, Venkata Raman Vollala, Satheesha Nayak, Mohandas Rao,Shreenivasa Rao Bolla, Narendra Pammidi: A rare variation in branching pattern of axillary artery, letter to editor, Indian journal of plastic surgery July- Dec2006, vol 39 (2)

[11] Feinberg RN. Vascular development in the embryonic limb bud. In: Feinberg RN, Sherer GK, Auerbach R, Eds. The development of the vascular system. Basel, Karger (Issues Biomed). 1991; 14: 136-148.

[12] Rodriguez-Baeza A, Nebot J, Ferreira B, Reina F, Perez J, Sanudo JR, Roig M. An anatomical study and ontogenetic explanation of 23 cases with variations in the main pattern of the human brachio-antebrachial arteries. J Anat. 1995; 187: 473-479.

[13] González-Compta X: Origin of the radial artery from the axillary artery and associated hand vascular anomalies. Journal of Hand Surgery 16A, 1991, 293-296.

\section{Legends for figures:}

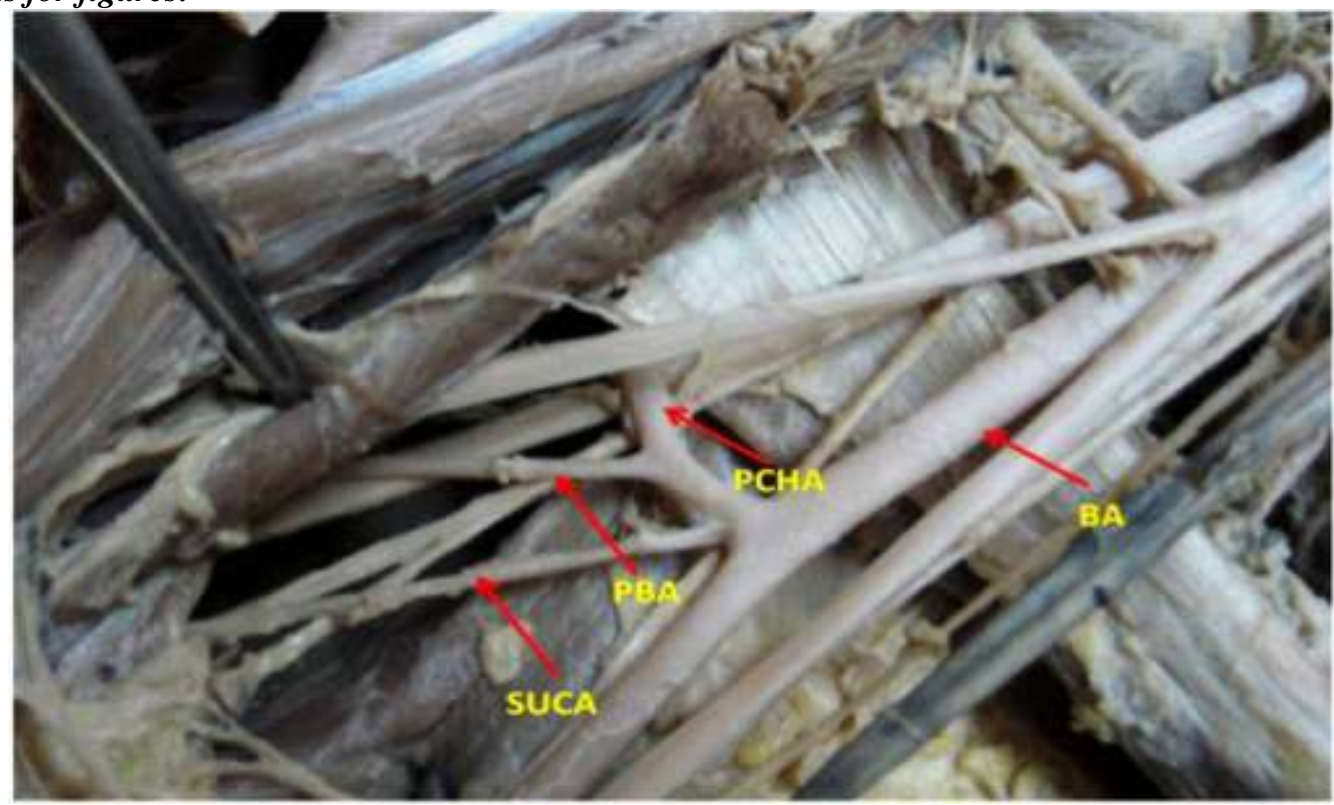

Figure :1 Variant branches from BA arising in upper third of arm. B A-brachial artery, PCHA - posterior circumflex humeral artery, PBA - profunda brachii artery,SUCA-Superior ulnar collateral artery.

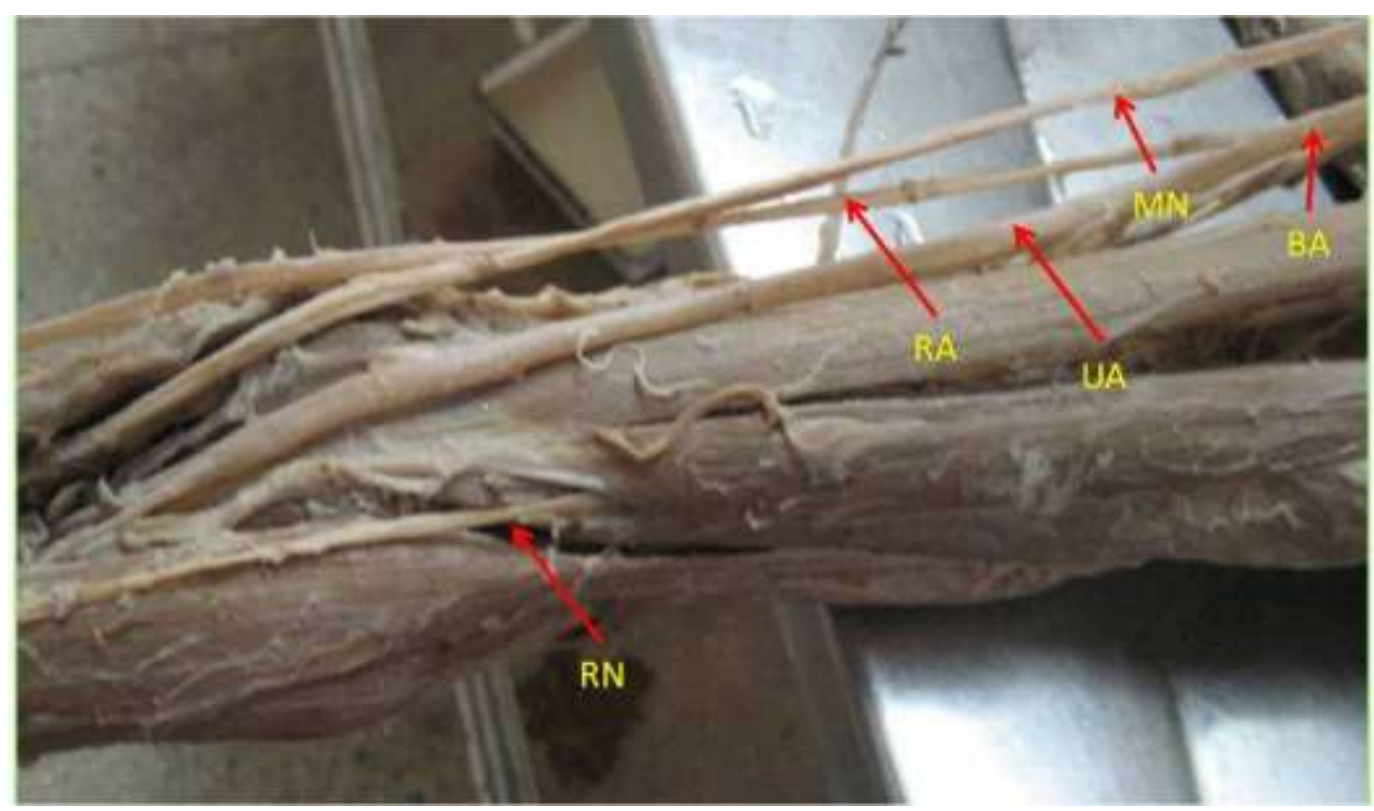

Figure :2High division of B A-brachial artery into RA-radial artery and UA- ulnar artery RN-radial nerve (superficial branch).MN - musculocutaneous nerve passing from lateral to medial side, over radial artery as descends to cubital fossa. 